\title{
Fast and Efficient Separation and Determination of UV-absorbing Amino Acids, Nucleobases, and Creatinine Using a Carboxy- functionalized Cation-exchange Column
}

\author{
Yukio Yoкоуама, ${ }^{* \dagger}$ Takeru FuJISHIMA, ${ }^{* *}$ and Kazuki Kurota* \\ *Department of Analytical Chemistry, Graduate School of Environment and Information Sciences, \\ Yokohama National University, 79-7 Tokiwadai, Hodogaya, Yokohama 240-8501, Japan \\ **College of Engineering Science, Yokohama National University, 79-5 Tokiwadai, Hodogaya, \\ Yokohama 240-8501, Japan
}

\begin{abstract}
This paper presents a new HPLC technique for the determination of biogenic cations such as amino acids and nucleobases, using a weak-acid cation-exchange column. Fourteen analytes, five amino acids and seven bases in addition to creatinine and creatine, were separated in $12 \mathrm{~min}$ by means of a two-liquid gradient elution with UV detection. The newly released column packed with a carboxy-functionalized polymethacrylate resin could give excellent selectivity to the organic cations of interest, although such a column is in general suitable for the separation of inorganic common cations. The chromatographic intra-day repeatability was very good with RSDs less than $0.4 \%$, and the quantitation precision based on peak area intensities was also good with RSDs less than 5\% for all analytes. The linear calibration lines for quantitation ranged between 5 and $500 \mu \mathrm{M}$ on $20-\mu \mathrm{L}$ injections with $R^{2}$ more than 0.9990 . Since the method could provide concentration data of urinary creatinine and some metabolites simultaneously, for example, the urinary phenylalanine/ creatinine ratios for phenylketonuria of inborn errors of metabolism were simply determined through one chromatographic run. The ratios for patients were significantly higher than those for controls. We found that the new weak-acid cationexchange column was suitable for the separation of organic cations as well as inorganic cations.
\end{abstract}

Keywords HPLC, carboxy-functionalized cation-exchange column, amino acids, nucleobases, phenylalanine/creatinine ratio, phenylketonuria

(Received November 20, 2014; Accepted February 19, 2015; Published May 10, 2015)

\section{Introduction}

It has been a long time since cation-exchange column chromatography of amino acids was automated by Moore, Spackman, and Stein. ${ }^{1,2}$ It took $24 \mathrm{~h}$ in those days to separate protein hydrolysates. Nowadays, an amino-acid analyzer based on cation-exchange chromatography can provide, in general, separation in $1 \mathrm{~h}$. On the one hand, we have proposed lowcapacity cation-exchange chromatography techniques ${ }^{3-6}$ for the analyses of biogenic cations such as amino acids and creatinine, using low-capacity sulfoacylated ${ }^{7,8}$ macroreticular styrenedivinylbenzene copolymers. Such low-capacity columns can facilitate a 50-min separation of underivatized proteinogenic amino acids using a binary gradient high-performance liquid chromatography (HPLC). ${ }^{4}$ After this, a more efficient and selective packing material was developed, ${ }^{9}$ and a 23 -min separation of 17 underivatized proteinogenic amino acids was attained with a resolution of 1.0 for critical peak pair (isoleucine and leucine), using a self-made polyfunctional low-capacity cation-exchange column. This can provide cost-effective results or information for the high-risk screening or chemical diagnosis

$\dagger$ To whom correspondence should be addressed.

E-mail: yokyuk@ynu.ac.jp of inborn errors of amino-acid metabolism..$^{10,11}$

However, since such polyfunctional materials are unavailable from the market at present, several low-capacity cation-exchange packing materials, being selective to organic cations such as amino acids, nucleobases, and nucleosides, have been newly designed and developed jointly with a column-packing manufacturer. From the cooperative studies, a new HPLC method for simultaneous determination of UV-absorbing urinary metabolites such as histidine derivatives, aromatic amino acids and creatinine have been presented, ${ }^{12}$ which allows for the determination of the analyte/creatinine ratios for diagnostic marker amino acids through a single chromatographic run. Since the ionic characteristics of amino acids and nucleobases are very similar each other, it is difficult to isolate them into different fractions even if a cation-exchange preparative pretreatment is performed for urine samples. ${ }^{13,14}$ Therefore, it is useful to construct a simultaneous separation method for such organo-cationic species coexisting in biogenic fluids. Reported in recent years have been some LC methods targeting nucleosides and/or nucleobases ${ }^{15-19}$ or amino acids ${ }^{4,9,20,21}$ individually; however, a liquid chromatography method has not been reported so far except liquid chromatography/mass spectrometry (LC/ MS) methods with ${ }^{22}$ and without ${ }^{23}$ precolumn derivatization. As is often the case with LC/MS, the mass identification may make up the insufficient LC separation. The chromatographic 
separation should precede all detection methods including MS from the separation-science viewpoints; and is important and essential for the reproducible and cost-effective analysis of such organic cations.

This paper presents a new HPLC method for the simultaneous determination of UV-absorbing nucleobases, amino acids, and creatinine using a newly designed cation-exchange column packed with a carboxy-functionalized poly-methacrylate resin. Since, in general, such carboxy-type columns are exclusively used for the simultaneous separation of alkali and alkaline-earth metal ions, namely common cations including ammonium ion, their selectivity to organic cations is still unknown or unexploited in the ion chromatography world. It is the point of this work that the hidden selectivity of the carboxy-type column to biogenic cations has been discovered from our column evaluation study. A fast and efficient chromatography method was constructed using a new ion-chromatography column, which could provide the significant phenylalanine (a diagnostic marker)/creatinine ratios for urine samples from newborn patients with phenylketonuria of inborn errors of metabolism, as an example of application to real samples.

\section{Experimental}

\section{Reagents and chemicals}

L-Histidine (His), L-methionine (Met), L-phenylalanine (Phe), L-tryptophan (Trp), L-tyrosine (Tyr), creatine (Crn), creatinine (Cre), uracil (Ura), thymine (Thy), xanthine (Xan), hypoxanthine (Hyp), cytosine (Cyt), guanine (Gua), and adenine (Ade) were purchased from Wako Pure Chemicals (Osaka, Japan) or Tokyo Kasei (Tokyo, Japan). Phosphoric acid of guaranteed grade was obtained from Wako Pure Chemicals. Acetonitrile of HPLC grade and ethylenediamine (EDA) of $99.5 \%$ grade were acquired from Sigma-Aldrich Japan (Tokyo, Japan).

\section{Urine samples}

Five urine samples from patients with phenylketonuria (PKU), and five control urine samples from healthy newborns were subjected to the analysis. They were preliminarily separated into their basic fractions, leading to a considerable dilution of the intact urine. The separation and cleanup procedure has been described in our previous paper. ${ }^{13,14}$ Also, a direct injection of urine sample pretreated simply by filtration with a $0.2-\mu \mathrm{m}$ filter (HP020AN, Advantec, Tokyo, Japan) was available as demonstrated in this application study.

\section{Analytical column}

A Mitsubishi Chemical Corp. (Tokyo, Japan) MCI ${ }^{\circledR} \mathrm{GEL}$ CHK45/C04 column packed with carboxy-functionalized polymethacrylate cation-exchange resin (functional group: dicarboxylic acid; particle size: $4 \mu \mathrm{m}$ in average; dimension: $4.6 \mathrm{~mm} \times 150 \mathrm{~mm}$; pressure limit: $12 \mathrm{MPa}$, available $\mathrm{pH}$ : 2 12) was furnished by courtesy of the manufacturer. Such a carboxylic-acid type column is in general suitable for the separation of common cations, such as $\mathrm{Na}^{+}, \mathrm{NH}_{4}{ }^{+}, \mathrm{K}^{+}, \mathrm{Mg}^{2+}$, and $\mathrm{Ca}^{2+}$. The separating power of it was compared with that of a Tosoh (Tokyo, Japan) TSKgel IC-Cation I/II HR (carboxyl-type cation-exchange column, particle size: $5 \mu \mathrm{m}, 4.6 \mathrm{~mm} \times$ $100 \mathrm{~mm}$ ), a preceding commercially available ion chromatography column for common cations. To begin by stating the conclusion, the two materials were similar but different in the selectivity to organic cations.
Table 1 An optimized gradient elution time program

\begin{tabular}{cccl}
\hline Time $/ \mathrm{min}$ & $\% \mathrm{~A}$ & $\% \mathrm{~B}$ & \multicolumn{1}{c}{ Status } \\
\hline $0.0 \rightarrow 0.8$ & 100 & 0 & Hold \\
$0.9 \rightarrow 3.0$ & 90 & 10 & Hold \\
$3.0 \rightarrow 5.0$ & $90 \rightarrow 40$ & $10 \rightarrow 60$ & Linear \\
$5.0 \rightarrow 6.0$ & 40 & 60 & Hold \\
$6.0 \rightarrow 6.5$ & $40 \rightarrow 30$ & $60 \rightarrow 70$ & Linear \\
$6.5 \rightarrow 10.0$ & 30 & 70 & Hold \\
$10.0 \rightarrow 15.0$ & 100 & 0 & Initializing \\
\hline
\end{tabular}

A. $6 \mathrm{~mm} \mathrm{H}_{3} \mathrm{PO}_{4} / 0.7 \mathrm{mM} \mathrm{EDA} / 5 \%$ (v/v) $\mathrm{CH}_{3} \mathrm{CN}$.

B. $6 \mathrm{~mm} \mathrm{H}_{3} \mathrm{PO}_{4} / 0.7 \mathrm{mM} \mathrm{EDA} / 35 \%$ (v/v) $\mathrm{CH}_{3} \mathrm{CN}$.

\section{Apparatus}

The binary gradient HPLC system consisted of a Hitachi (Tokyo, Japan) L-7100 four-liquid delivery pump; L-7610 degasser; L-7200 column oven; L-7400 UV-Vis spectrometric detector; a Rheodyne (Cotati, CA) 7725i syringe loading sample injector with a $100-\mu \mathrm{L}$ loop; a Runtime Instruments (Sagamihara, Japan) Chromato-PRO data processing device and software working under a Windows ${ }^{\circledR}$ environment.

\section{Chromatographic conditions}

Two solvents, A: $6 \mathrm{mM} \mathrm{H}_{3} \mathrm{PO}_{4} / 0.7 \mathrm{mM} \mathrm{EDA} / 5 \%$ (v/v) $\mathrm{CH}_{3} \mathrm{CN}$ and B: $6 \mathrm{mM} \mathrm{H}_{3} \mathrm{PO}_{4} / 0.7 \mathrm{mM} \mathrm{EDA} / 35 \%$ (v/v) $\mathrm{CH}_{3} \mathrm{CN}$ were used as the mobile phase. Binary gradient elution systems were established by optimizing a gradient program for the solvent delivery ratios at a constant flow rate $(1.0 \mathrm{~mL} / \mathrm{min})$ as listed in Table 1. Other conditions were as follows: UV detection wavelength: $210 \mathrm{~nm}$; column temperature: $40^{\circ} \mathrm{C}$; sample size: 20 or $10 \mu \mathrm{L}$ (by micro-syringe scale).

\section{Results and Discussion}

\section{Fundamental column performance}

The fundamental performance of the carboxy-functionalized cation-exchange resin of interest was characterized in advance of the optimization study for the separation of organic cations. Although the overall molar concentration of the carboxy groups, i.e. whole capacity by cation-exchangeable functional groups, in weak-acid cation-exchange resins is in general very high, e.g., exceeding $1 \mathrm{~mol} / \mathrm{L}-$ resin, the working cation-exchange sites under a weakly acidic $\mathrm{pH}$ condition on cation chromatography are thought to be very small, e.g., in the order of mmol/L-resin or less. We recently have developed a capacity analyzing system, ${ }^{24}$ which looks like an ion-chromatography system without sample injector, and also have improved the equilibration buffer system. ${ }^{9}$ This can provide a dynamic capacity curve, that is, plots of the changes in dynamic exchange capacities (DECs) over the column effluent $\mathrm{pH}$ after equilibration with several buffer solutions. The mole flux of $\mathrm{H}^{+}$required for exchanging from $\mathrm{Na}^{+}$-form to $\mathrm{H}^{+}$-form of the cation-exchange resin (molar concentration $\times$ time $\times$ flow-rate) can correspond to the dynamic cation-exchange capacity ${ }^{24}$ under the buffer $\mathrm{pH}$ conditions subjected. The prefixed term dynamic implies the effective capacity on the chromatography process. Figure 1 shows DEC curves of the two carboxy-functionalized cation-exchange packing materials for $\mathrm{MCI}^{\circledR} \mathrm{GEL}$ CHK45/C04 of interest and TSKgel IC-Cation I/II HR as reference. The cation exchange capacities were naturally dependent on the surrounding $\mathrm{pH}$ in columns; or the DECs increased accordingly as the $\mathrm{pH}$ increased. Both curves look similar. The slope of the increase became 


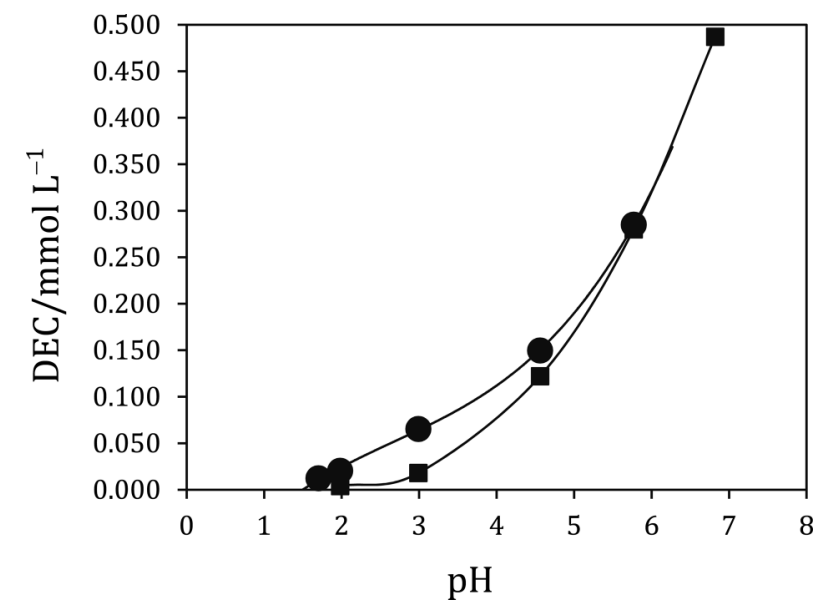

Fig. 1 Dynamic capacity curves for the carboxy-functionalized resins in $\mathrm{MCI}^{\circledR} \mathrm{GEL}$ CHK45/C04 (•) and TSKgel IC-Cation I/II HR $(\mathbf{\square})$

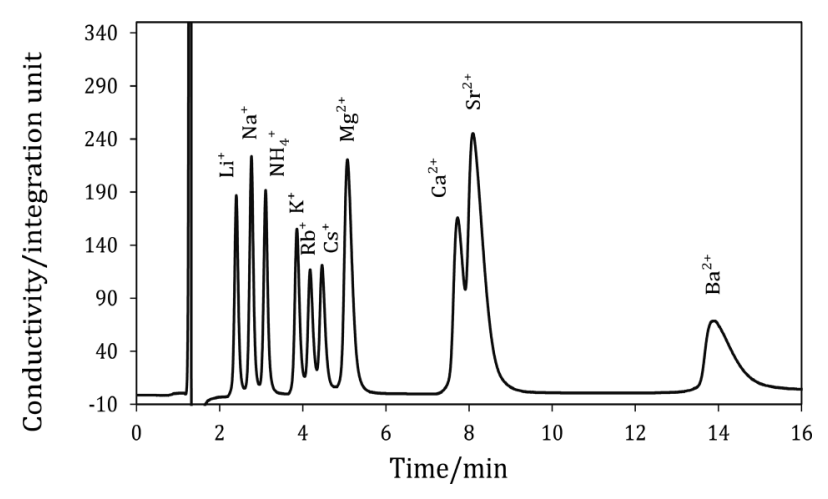

Fig. 2 A typical ion chromatogram of alkali, magnesium, and alkaline-earth cations and ammonium ion. Conditions: eluent, $4.0 \mathrm{mmol} / \mathrm{L} \mathrm{H}_{2} \mathrm{SO}_{4}$; flow rate, $1.2 \mathrm{~mL} / \mathrm{min}$; column temperature, $40^{\circ} \mathrm{C}$; detection, electric conductivity; sample size, $20 \mu \mathrm{L}$. Concentration: $1.0 \mathrm{mmol} / \mathrm{L}$ in each.

steep when exceeding $\mathrm{pH}$ 6; and the measurement became timeconsuming and difficult over $\mathrm{pH} 7$ because the dissociation of carboxy groups is highly promoted under alkaline conditions. In the CHK45/C04, the working capacity for the separation of common cations under an eluting condition around $\mathrm{pH} 2$ by sulfuric acid was actually in $20 \mathrm{mmol} / \mathrm{L}$-resin level or lower; and that for amino acids and nucleobases in this study was also in low level around $50 \mathrm{mmol} / \mathrm{L}-$ resin (at $\mathrm{pH} 2.5$ ). On the other hand, the working capacity of IC-Cation I/II HR under acidic conditions was lower than that of CHK45/C04. Such dynamic capacity curves exposed here, probably for the first time, can provide very suggestive and characteristic information for weakacid cation-exchange materials, compared to those obtained by a classical batch titration method. ${ }^{25}$

The fundamental column performance was ascertained by separating $\mathrm{Li}^{+}, \mathrm{Na}^{+}, \mathrm{NH}_{4}{ }^{+}, \mathrm{K}^{+}, \mathrm{Rb}^{+}, \mathrm{Cs}^{+}, \mathrm{Mg}^{2+}, \mathrm{Ca}^{2+}, \mathrm{Sr}^{2+}$, and $\mathrm{Ba}^{2+}$ by $4.0 \mathrm{mmol} / \mathrm{L}_{2} \mathrm{SO}_{4}$ at $1.2 \mathrm{~mL} / \mathrm{min}$ (by the supplier's recommendation), as shown in Fig. 2, which could give substantially good separations for them in approximately 14 min. Although the separation between $\mathrm{Ca}^{2+}$ and $\mathrm{Sr}^{2+}$ was poor, we thought that it would not be seen a big defect for general onsite analyses because $\mathrm{Sr}^{2+}$ is less abundant in our natural environment. On the other hands, an IC-Cation I/II HR column could separate such inorganic cations in $25 \mathrm{~min}$ by $2.0 \mathrm{mmol} / \mathrm{L} \mathrm{HNO}_{3}$ at $0.80 \mathrm{~mL} / \mathrm{min}$ (also by the supplier's recommendation); however, this column was less suitable for the separation of organic cations such as amino acids and nucleobases.

\section{Binary gradient elution}

A binary gradient elution condition was studied for the separation of the 14 analytes listed in the Experimental section. Since the ion-exchange reaction occurring between mobile and stationary phases is relatively slow due to the diffusion-control process of ions, a lower flow rate, typically $0.3-0.5 \mathrm{~mL} / \mathrm{min}$, is recommended in amino-acid separation based on cationexchange chromatography. Therefore, the flow rate was set at $0.50 \mathrm{~mL} / \mathrm{min}$ in the first optimization study. On the one hand, the UV detection at $260 \mathrm{~nm}$ is specific to nucleobases; however, UV $210 \mathrm{~nm}$ was commonly used considering the UV sensitivity of aromatic amino acids and creatinine..$^{5,6}$

In order to select a set of the binary solvent system A and B, the 14 analytes were classed into three groups, i.e., six weakly retained species (W): Ura, Thy, Xan, Hyp, Met, and Crn; four moderately retained species (M): His, Cre, Cyt, and Tyr; and four strongly retained species (S): Gua, Phe, Ade, and Trp. The compositions of the solvents were individually fixed by considering their isocratic separation data; and the final gradient program for the two solvent-delivery pumps was optimized after much study with trial and error. Since the cation-exchange interaction may occur on a low-capacity region, a phosphate buffer system of relatively low concentration is recommended because of its suitable eluting power. ${ }^{4,9,12}$ The phosphoric acid concentration and acetonitrile content were major parameters for the selection of the mobile phase $\mathrm{A}$ and $\mathrm{B}$. The various combinations of $\mathrm{H}_{3} \mathrm{PO}_{4}$ between 5 and $20 \mathrm{mmol} / \mathrm{L}$ and $\mathrm{CH}_{3} \mathrm{CN}$ between 1.5 and $18 \%(\mathrm{v} / \mathrm{v})$ were examined to obtain good separations for the groups (W) and (M) analytes. Since the addition of ethylenediammonium ion into the mobile phase has been effective to shorten or change retention times of basic amino acids, such as His, without any peak tailings, ${ }^{12}$ the optimum concentration of EDA in the acidic mobile phases was studied systematically. From the many isocratic elution results for the individual analyte groups, the three parameters for the mobile phases were determined as (A) $6 \mathrm{mM} \mathrm{H}_{3} \mathrm{PO}_{4} / 0.7 \mathrm{mM}$ EDA/5\% (v/v) $\mathrm{CH}_{3} \mathrm{CN}$ and (B) $6 \mathrm{mM} \mathrm{H}_{3} \mathrm{PO}_{4} / 0.7 \mathrm{mM} \mathrm{EDA} / 35 \%$ (v/v) $\mathrm{CH}_{3} \mathrm{CN}$. Considering the isocratic data, the time program for binary gradient elution was carefully optimized, which could lead to a good separation in $25 \mathrm{~min}$.

Although such a 25 -min separation of the 14 analytes may be practically acceptable for the analyses of real samples, ${ }^{9,12}$ there is the possibility of improving chromatographic run time; this is because the column used can permit a high flow-rate elution at $1.2 \mathrm{~mL} / \mathrm{min}$ as used in the separation of inorganic cations without a decrease in chromatographic resolution. Therefore, the flow rate was set at $1.0 \mathrm{~mL} / \mathrm{min}$ to establish a more highspeed separation, considering the upper limit of the column back pressure. As a result, it was found that the chromatographic resolution was almost unchanged by increasing the flow rate. However, a minor change in the binary gradient program was necessary for more excellent separations. The final optimized time program is listed in Table 1. A high-speed separation of the standard mixture was established in approximately $12 \mathrm{~min}$ with resolution more than 1.3 (of the critical peak pair, Tyr-Cre) as shown in Fig. 3. The back pressure varied between 7.5 and 9.0 $\mathrm{MPa}$ during the chromatographic run. In addition, because the re-equilibration of the column required about $3 \mathrm{~min}$, the 
chromatographic cycle time was as short as around $15 \mathrm{~min}$.

On the other hand, the dual-mode gradient elution technique ${ }^{5,12,26}$ has been useful for more high-speed separation. However, such a technique could contribute to saving only $1 \mathrm{~min}$ in time for the chromatographic run. Therefore, the single-mode gradient was employed in this work for generality.

\section{Method validation}

The binary gradient HPLC method for the determination of the 14 biogenic metabolites was very reproducible and quantitative, as given in Table 2. The intra-day repeatability of chromatography was very good within $0.4 \%$ of RSD of retention times for each analyte, which could imply that the cycle time was adequately defined. The peak area intensities within day based on a vertical-partition integration for adjacent peaks were also precise for the determination of the analytes with less than $5 \%$ of RSD. The inter-day reproducibility for both was somewhat lower, probably due to eluent re-preparations. Since nucleobases, especially Gua, seemed to be unstable in the

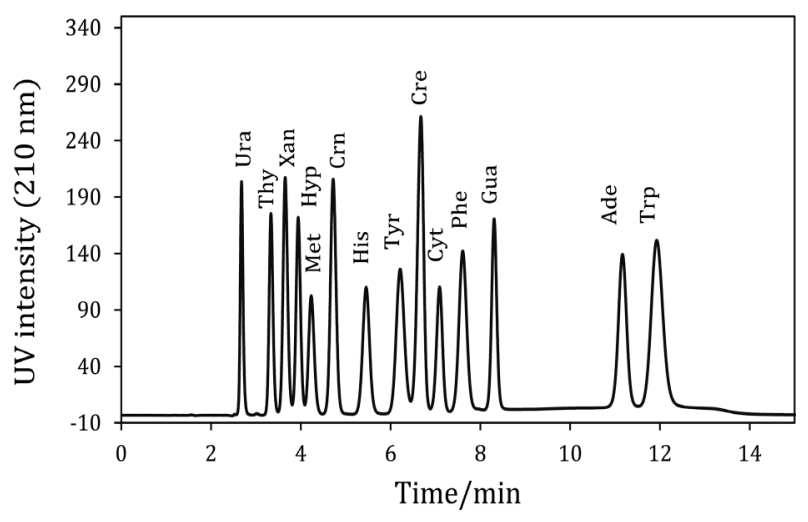

Fig. 3 A binary gradient chromatogram of the 14 analytes. Mobile phase: as in Table 1; flow rate, $1.0 \mathrm{~mL} / \mathrm{min}$; column temperature, $40^{\circ} \mathrm{C}$; detection, UV $210 \mathrm{~nm}$; sample size, $20 \mu \mathrm{L}$. Concentration: $0.10 \mathrm{mM}$, nucleobases and Trp; $0.20 \mathrm{mM}$, His, Phe, and Tyr; $0.50 \mathrm{mM}$, Cre, Crn, and Met. standard mixture (probably due to solubility), the inter-day area reproducibility was relatively poor. The linear range of calibration line for each was practical with a determination coefficient $\left(R^{2}\right)$ of over 0.9990.

The method was sensitive for the UV-absorbing analytes of $2-18$ pmol (in $20 \mu \mathrm{L}$ ) in detection limits (LODs). The quantitation limits (LOQs) were definable to be three times higher than LODs. The recovery data were obtained by spiking the standard mixture to 10 different intact urine samples. Although a little matrix effect was observed in some cases, the recovery seemed to be acceptable. However, it may be necessary to perform preliminary separation of the basic species from some hydrophobic acidic metabolites that can interfere with the quantitation. This is discussed in the following Application section.

\section{Application to PKU urine samples}

Since the urinary nucleobases seemed to be less abundant compared to amino acids, the method utility was demonstrated by analyzing a diagnostic marker amino acid in urine samples from several patients with PKU, and from healthy newborns as controls. Figures 4 and 5 show typical chromatograms for control and PKU urine samples, respectively, obtained by injecting a $10-\mu \mathrm{L}$ aliquot of the intact urine after subjecting $0.2-\mu \mathrm{m}$ filtration. The intense and common peaks appearing in both groups of urine samples within $3 \mathrm{~min}$ are probably due to UV-sensitive organic acids of normal urinary metabolites. Therefore, the 13 analytes other than uracil may be less influenced even without preliminary fractionation treatment. ${ }^{13,14}$ Figure 6 shows a chromatogram of a basic fraction of a PKU urine (see Experimental). The common peaks weakly retained, as seen in Figs. 4 and 5, disappeared in Fig. 6. The intense and diagnostic peak of phenylalanine was distinctive in Figs. 5 and 6.

Creatinine is a normal metabolite excreted in urine, and is used as an internal standard to correct spot urine samples containing some target metabolites of interest. Since urine contains various kinds of organic species, the standard addition method was useful for the determination of creatinine and phenylalanine (a diagnostic marker of PKU) in this work to reduce some matrix effects. The quantitation results are

Table 2 Validation data for the binary gradient HPLC method

\begin{tabular}{|c|c|c|c|c|c|c|c|c|}
\hline \multirow{3}{*}{ Analyte } & \multicolumn{4}{|c|}{ Precision, \%RSD $(n=7)$} & \multirow{3}{*}{$\begin{array}{c}\text { Test range/ } \\
\mu^{\mathrm{a}}\end{array}$} & \multirow{3}{*}{$R^{2}$} & \multirow{3}{*}{$\begin{array}{c}\mathrm{LOD}^{\mathrm{a}} / \\
\mu \mathrm{M}\end{array}$} & \multirow{3}{*}{$\begin{array}{c}\text { Recovery, \% } \\
\quad(n=10)\end{array}$} \\
\hline & \multicolumn{2}{|c|}{ Retention time } & \multicolumn{2}{|c|}{ Area response } & & & & \\
\hline & Intra-day & Inter-day & Intra-day & Inter-day & & & & \\
\hline Ura & 0.21 & 0.72 & 1.7 & 2.8 & $5-500$ & 0.9993 & 0.08 & 98 \\
\hline Thy & 0.28 & 0.56 & 0.8 & 1.4 & $5-500$ & 0.9990 & 0.09 & 91 \\
\hline Xan & 0.22 & 0.48 & 0.8 & 6.9 & $5-500$ & 0.9998 & 0.88 & 101 \\
\hline Нyp & 0.24 & 0.43 & 1.0 & 4.3 & $5-500$ & 0.9994 & 0.11 & 98 \\
\hline Met & 0.19 & 0.50 & 0.8 & 2.4 & $5-500$ & 0.9991 & 0.70 & 113 \\
\hline Crn & 0.17 & 0.45 & 1.7 & 1.2 & $5-500$ & 0.9997 & 0.62 & 82 \\
\hline His & 0.11 & 0.42 & 1.5 & 2.3 & $5-500$ & 0.9994 & 0.33 & 95 \\
\hline Tyr & 0.29 & 0.76 & 1.1 & 1.4 & $5-500$ & 0.9996 & 0.29 & 101 \\
\hline Cre & 0.21 & 0.52 & 1.9 & 1.1 & $5-500$ & 0.9993 & 0.34 & 95 \\
\hline Cyt & 0.31 & 0.66 & 1.1 & 2.7 & $5-500$ & 0.9996 & 0.12 & 103 \\
\hline Phe & 0.36 & 0.88 & 2.0 & 4.3 & $5-500$ & 0.9992 & 0.27 & 80 \\
\hline Gua & 0.42 & 0.88 & 2.0 & 11.4 & $5-500$ & 0.9996 & 0.10 & 95 \\
\hline Ade & 0.41 & 0.73 & 4.6 & 6.2 & $5-500$ & 0.9991 & 0.12 & 84 \\
\hline Trp & 0.25 & 1.25 & 1.5 & 4.3 & $1-100$ & 0.9998 & 0.07 & 109 \\
\hline
\end{tabular}

a. On the sample size $20 \mathrm{~mL}$. 


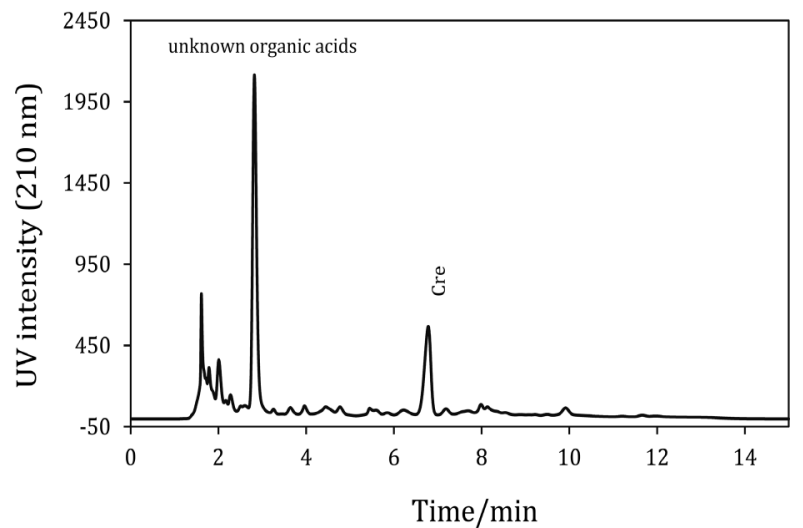

Fig. 4 Typical chromatogram of urine from a healthy newborn after $0.2-\mu \mathrm{m}$ filtration. Sample size was $10 \mu \mathrm{L}$.

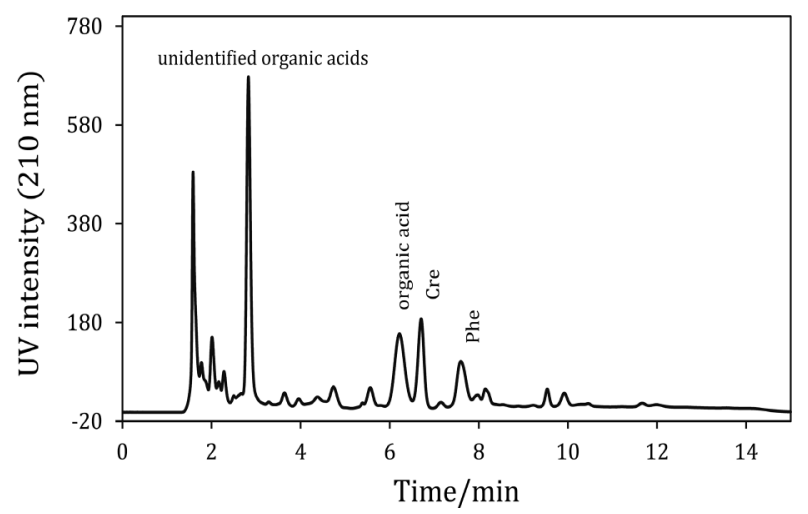

Fig. 5 Typical chromatogram of urine from a patient with PKU after $0.2-\mu \mathrm{m}$ filtration. Sample size was $10 \mu \mathrm{L}$.

summarized in Table 3. Since the method can provide concentrations of creatinine and amino acids simultaneously, the analyte/creatinine ratios are easily determined for chemical diagnosis of inborn errors of metabolism such as PKU.

The phenylalanine/creatinine ratios for PKU urine samples $(0.42-0.88)$ were significantly higher than those for healthy urine samples $(0.025-0.073)$, which could be simply calculated from their area integration data. Although the urine samples analyzable are limited by our laboratory because we are not a medical department or part of a hospital, it is undeniable that the method can provide the conclusive information for the diagnoses of several kinds of inborn errors of amino-acid metabolism such as PKU (marker, phenylalanine), tyrosinemia (tyrosine), homocystinuria (methionine), and so on, with single chromatographic runs. Although the standard addition method has been effectively subjected to the intact urine this time, some preliminary separations are more effective, but are timeconsuming, to remove several UV-sensitive organic acids that can interfere with amino acids as seen in Fig. 5. The peaks observed in Fig. 6 are all of organic cations.

\section{Conclusions}

The present HPLC method can provide the simultaneous determination of creatinine and UV-absorbing biogenic cations such as nucleobases and amino acids, while urinary creatinine is in general analyzed by means of a traditional spectrophotometric

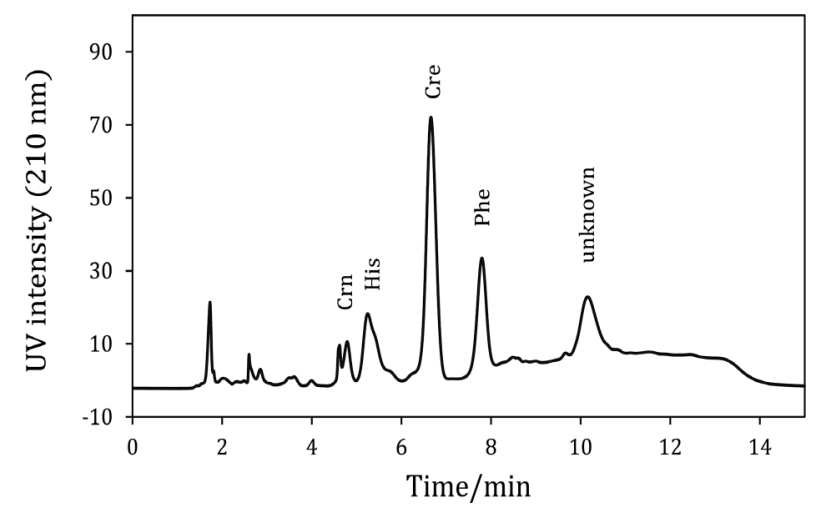

Fig. 6 Chromatogram of a basic fraction of urine of patient with PKU after separating acidic and/or neutral metabolites. Sample size corresponds to one fifth of intact urine.

Table 3 Concentrations of creatinine and phenylalanine found in urine samples from PKU patients and healthy newborns by standard addition method

\begin{tabular}{cccc}
\hline PKU & Cre/mM $\left(R^{2}\right)$ & Phe/mM $\left(R^{2}\right)$ & Phe/Cre \\
\hline 1 & $2.01(1.0000)$ & $1.64(0.9999)$ & 0.82 \\
2 & $3.63(0.9997)$ & $1.82(0.9995)$ & 0.50 \\
3 & $0.36(0.9995)$ & $0.32(0.9995)$ & 0.88 \\
4 & $1.33(0.9994)$ & $0.79(0.9918)$ & 0.59 \\
5 & $1.28(1.0000)$ & $0.54(0.9997)$ & 0.42 \\
\hline \multirow{2}{*}{ Control } & Cre/mM $\left(R^{2}\right)$ & Phe/mM $\left(R^{2}\right)$ & Phe/Cre \\
\hline 1 & $4.66(0.9980)$ & $0.15(0.9997)$ & 0.032 \\
2 & $1.75(1.0000)$ & $0.13(1.0000)$ & 0.073 \\
3 & $2.37(0.9994)$ & $0.16(0.9987)$ & 0.067 \\
4 & $1.30(0.9994)$ & $0.03(1.0000)$ & 0.025 \\
5 & $2.34(1.0000)$ & $0.15(0.9946)$ & 0.064 \\
\hline
\end{tabular}

method. ${ }^{27}$ The present method is cost-effective and eco-friendly, and has analytical merit providing significant analyte/creatinine ratios through one chromatographic run. If the UV detection wavelength is set at $260 \mathrm{~nm}$, the selectivity to nucleobases is improved optically, in which the use of diode-array UV-Vis detector is recommended. If the post-column derivatization detection, for example $o$-phthalaldehyde fluorescence detection, is used, the sensitivity and selectivity to amino acids can considerably increase. In addition, if the column effluent is monitored with a conductivity detector, inorganic cations such as $\mathrm{Na}^{+}$and $\mathrm{Ca}^{2+}$ in biological fluids are analyzable using the same column with a sulfuric acid eluent (see above). In addition, the column performance has been almost unchanged for a long period through this optimization study carried out often under severe conditions for the stationary phase. We can conclude that this kind of carboxy-functionalized $\mathrm{CHK} 45 / \mathrm{C} 04$ column is suitable for the analyses of both organic and inorganic cations. We have found the diversity of the column; and study on further developments in separation is now under way, and the results will appear in due course.

\section{Acknowledgements}

This work was partly supported by grants based on a joint research project with Mitsubishi Chemical Corp. We thank 
Mr. Ryuichi Sugimoto, Mr. Akihiro Shimura, and Miss Yuka Yoshidzumi of Mitsubishi Chemical Corp. for participating in helpful discussions and providing information for the analytical column.

\section{References}

1. S. Moore, D. H. Spackman, and W. H. Stein, Anal. Chem., 1958, 30, 1185.

2. D. H. Spackman, W. H. Stein, and S. Moore, Anal. Chem., 1958, 30, 119.

3. Y. Yokoyama, M. Watanabe, S. Horikoshi, and H. Sato, Anal. Sci., 2002, 18, 59.

4. Y. Yokoyama, N. Wakabayashi, Y. Furugaki, and H. Sato, Anal. Sci., 2004, 20, 1189.

5. Y. Yokoyama, S. Tsuji, and H. Sato, J. Chromatogr. A, 2005, 1085, 110.

6. Y. Yokoyama, K. Yamasaki, and H. Sato, J. Chromatogr. B, 2005, 816, 333.

7. A. Seubert and A. Klingenberg, J. Chromatogr. A, 1997, $782,149$.

8. A. Klingenberg and A. Seubert, J. Chromatogr. A, 1998, 804, 63.

9. Y. Yokoyama, A. Yokokawa, K. Noguchi, and T. Tanabe, Talanta, 2013, 103, 245.

10. R. A. Chalmers, P. Purkiss, R. W. E. Watts, and A. Lawson, J. Inherited Metab. Dis., 1980, 3, 27.

11. D. Wellner and A. Meister, Ann. Rev. Biochem., 1981, 50, 911.
12. Y. Yokoyama, R. Kanazawa, and H. Ukishima, Chromatographia, 2014, 77, 51.

13. Y. Yokoyama, H. Sato, and M. Tsuchiya, J. Chromatogr., 1991, 566, 19

14. Y. Yokoyama, N. Ohmori, and M. Tsuchiya, J. Mass Spectrom. Soc. Jpn., 1995, 43, 189.

15. S. P. Li, P. Li, C. M. Lai, Y. X. Gong, K. K. W. Kan, T. T. X. Dong, K. W. K. Tsim, and Y. T. Wang, J. Chromatogr. A, 2004, 1036, 239

16. L.-S. Li, M. Liu, S.-L. Da, and Y.-Q. Feng, Talanta, 2004 63, 433.

17. F. Q. Yang, J. Guan, and S. P. Li, Talanta, 2007, 73, 269.

18. L. Liua, J. Ouyanga, and W. R. G. Baeyensb, J. Chromatogr. A, 2008, 1193, 104.

19. S. Hou and M. Ding, Anal. Sci., 2010, 26, 1111.

20. H. Kaspar, K. Dettmer, W. Gronwald, and P. J. Oefner, Anal. Bioanal. Chem., 2009, 393, 445.

21. P. G. Rigas, Anal. Bioanal. Chem., 2013, 405, 7957.

22. A. Szterk and M. Roszko, J. Liq. Chromatogr. Relat. Technol., 2014, 37, 664.

23. H. Zhao, J. Chen, Q. Shi, X. Li, W. Zhou, D. Zhang, L. Zheng, W. Cao, X. Wang, and F. S.-C. Lee, J. Sep. Sci., 2011, 34, 2594.

24. T. Okabe and Y. Yokoyama, Anal. Sci., 2010, 26, 449.

25. H. Tamura, M. Kudo, and R. Furuichi, React. Funct. Polym., 1998, 38, 177.

26. Y. Yokoyama, S. Ozaki, and H. Sato, J. Chromatogr. A, 1996, 739, 333.

27. M. Jáffe, Z. Physiol. Chem., 1886, 10, 391. 